\title{
Consumer Preferences for Traditional, Neonicotinoid-free, Bee-friendly, or Biological Control Pest Management Practices on Floriculture Crops
}

\author{
Heidi M. Wollaeger ${ }^{1,4}$, Kristin L. Getter ${ }^{2}$, and Bridget K. Behe ${ }^{3}$ \\ Department of Horticulture, Michigan State University, 1066 Bogue Street, \\ East Lansing, MI 48824
}

Additional index words. bedding plants, beneficial insects, purchasing habits, conjoint analysis, likelihood-to-buy

\begin{abstract}
Neonicotinoids have recently been implicated by the media as a contributing factor to the decline of honey and bumblebees. We sought to better understand consumer perceptions and willingness to pay for traditional, neonicotinoid-free, bee-friendly, or biological control pest management practices as growers may seek alternative management practices to systemetic insecticides. We conducted a nationwide Internet survey $(n=3082)$, where consumers answered attitudinal, comprehension, likelihood-to-buy, and demographical questions about indoor (marketed in $10-\mathrm{cm}$ pots) and outdoor (marketed in $30-\mathrm{cm}$ hanging baskets or $10-\mathrm{cm}$ pots) floriculture products. The likelihood-to-buy questions were analyzed using conjoint analysis to determine which attributes had the greatest part-worth scores or which ones were viewed most positively by survey respondents. Of the total participants, $65.1 \%(n=2002)$ of the subjects had purchased an annual flowering plant in the $\mathbf{1 2}$ months before the survey. Respondents reported that the most important plant health and appearance factors that affect their purchasing decisions were that the flowering plants have no plant damage, while the second most important factor was that plants have no insects on them. The least important factor in the ranking of stated importance was that no neonicotinoid insecticides were used during the production of the plant. This finding may have resulted from $56.6 \%$ of all participants who reported that they did not understand the term. For those who viewed the indoor $10-\mathrm{cm}$ flowering plants $(n=1052)$, the plant species accounted for $41.2 \%$ of the decision to purchase the plant, followed by production type $(32.8 \%)$ and price $(26.0 \%)$. All three product attributes were of equal importance to the subjects who viewed the outdoor $10-\mathrm{cm}$ flowering plants $(n=1024)$, whereas only price had a lower relative importance when compared with production type and species for those who viewed the $30-\mathrm{cm}$ hanging baskets $(n=1006)$. Across all three studies, use of the term "bee-friendly" had the greatest economic value because it had the highest part-worth utility score, or the greatest willingness-to-buy. For the subjects who viewed the outdoor plants, "bee-friendly" and "use of beneficial insects" had greater economic value (with positive part-worth utility scores), but "neonicotinoid-free" and "traditional insect control" both had negative partworth utility scores, indicating they were valued less and detracted from the dollar value of the plant. The term "bee-friendly" was worth up to five times more to those respondents that had bought a plant in the last 12 months compared with those who had not. Therefore, if ornamental plants are labeled with pest management practices, most consumers value the term "bee-friendly" more and will likely discount products labeled "neonicotinoid-free."
\end{abstract}

Neonicotinoid insecticides are a class of insecticides that selectively act against piercing and sucking insect pests, such as

\footnotetext{
Received for publication 5 Dec. 2014. Accepted for publication 3 Mar. 2015.

We gratefully acknowledge funding from Project GREEEN. This project was supported by the USDA National Food and Agriculture, Hatch Project Number MICL 02085, and by Michigan State University AgBioResearch.

${ }^{1}$ Greenhouse Extension Educator. Current address: Michigan State University Extension, 3299 Gull Road, P.O. Box 42, Nazareth, MI 49074.

${ }^{2}$ Floriculture Outreach Specialist.

${ }^{3}$ Professor.

${ }^{4}$ To whom reprint requests should be addressed; e-mailwollaege@anr.msu.edu.
}

aphids, which are a common pest of crops (Tomizawa and Casida, 2005). The class of insecticides includes imidacloprid, acetamiprid, clothianidin, thiamethoxam, thiacloprid, dinotegruan, and nitenpyram (Blacquiere et al., 2012). Neonicotinoids are commonly used for pest control in crops and are chosen because of their low mammalian toxicity and their systemic properties that provide long-term plant protection (Tomizawa and Casida, 2005). The potential role of neonicotinoid insecticides in colony collapse disorder (CCD) in honeybees (Apis mellifera) and bumblebees (Bombus spp.) (Blacquiere et al., 2012) has received widespread attention, despite the lack of evidence of higher pesticide residuals in bee hives with CCD compared with those without CCD (van Engelsdorp et al., 2009). The possible implication of these pesticides in the reduction of pollinator populations may put social and political pressure, previously unseen in the industry (Cullen et al., 2008), on retailers to reduce or eliminate the use of neonicotinoid insecticides on ornamental plants. Such pressure may even increase governmental restrictions on neonicotinoid insecticides in the United States similar to those that already exist in Europe, where three neonicotinoid insecticides were restricted by the European Union in 2013 (Copping, 2013).

This negative publicity may have heightened consumer awareness of pesticide use in the horticulture industry, which may increase demand for products that are pesticide-free. Firms use labeling and signage to represent the value of extrinsic characteristics (e.g., price, brand, etc.) to consumers, such as those seen in "grown local" marketing campaigns (Behe et al., 2013; Yue et al., 2011). Labeling plants with new or novel production methods, such as reduced pesticides, may be one strategy to add economic value and enhance product differentiation to charge a premium for floriculture products.

Some consumers may value reduced pesticide usage compared with traditional production methods. In a survey of $\approx 400$ Canadian consumers, pest management was considered as the second most important factor $(\approx 25 \%$ relative importance) to price $(\approx 27 \%$ relative importance $)$ of both edible and non-edible greenhouse-grown crops (Grygorczyk et al., 2014). However, there were groups of consumers who believed that pest management practices were the most important factor for edible crops (24\%) and non-edible crops $(13.5 \%)$. In a separate study, consumers were willing to spend up to $\$ 485$ annually for the protection of eucalyptus species in the landscape with biological control pest management practices from the eucalyptus snout beetle. In contrast, participants reported that they would only be willing to spend $\$ 23$ for chemical management of the eucalyptus snout beetle (Jetter and Paine, 2004). Similarly, most consumers surveyed $(90 \%)$ in another study indicated they would pay $20 \%$ more for a pesticide-free pumpkin (Olson et al., 1995). While research has suggested that some consumers value reduced pesticide usage, the National Gardening Association (NGA) reported that 24\% of all U.S. households ( $\approx 29$ million) controlled insects on plants in 2012, an increase of 1 million households compared with the 5 -year average (28 million) (Butterfield and Baldwin, 2013). Furthermore, retail sales of insect control products increased from $\$ 1.693$ billion in 2011 to $\$ 1.772$ billion in 2012 , or about $5 \%$. The contrasting trend of increasing home owner insecticide use along with increasing preference for less pesticide use by plant producers may show that the importance of pest management methods is still secondary to plant quality. Consumers 
focus less on environmental impacts and still seek to control pests on their plants once they purchase them. However, they seem to be more skeptical about commercial growers' pest management practices.

In this study, our goal was to better understand consumer perceptions and willingness to pay a price premium for floriculture crops grown using different pest management practices including: traditional, neonicotinoid-free, bee-friendly, or biological control pest management practices. We investigated consumer's understanding of, and preferences for, plants grown with these production methods. We explored the importance of pest management practices relative to species and price in consumer's purchasing decisions. Finally, we investigated if there was a difference in preference or understanding of pest control practices among consumers who had and had not bought plants in the last 12 months.

\section{Materials and Methods}

Survey development. Three separate Internet surveys were developed in Qualtrics

Table 1. The likelihood to purchase attributes (species, price, and production method) with their respective levels for the three surveys (outdoor or indoor flowering plants in 10 -cm pots or 30 -cm hanging baskets).

\begin{tabular}{|c|c|c|}
\hline \multicolumn{3}{|c|}{$\begin{array}{l}\text { Production type } \quad \text { Attribute } \\
\text { Outdoor flowering plants in } 10-\mathrm{cm} \text { pots }\end{array}$} \\
\hline & Species & Viola spp. (pansy), Petunia $\times$ hybrida (petunia), Pelargonium $\times$ hortorum (geranium), Coreopsis spp. (coreopsis) \\
\hline & Price for a $10-\mathrm{cm}$ pot & $\$ 1.99, \$ 2.49, \$ 2.99, \$ 3.49$ \\
\hline & Insect management & Grown using: bee-friendly insect management, beneficial insects to control pests, no neonicotinoid insecticides, \\
\hline
\end{tabular}

Outdoor flowering plants in 30-cm hanging baskets or traditional insect management

Species

Petunia $\times$ hybrida (petunia), Impatiens hawkeri (new guinea impatiens), Pelargonium $\times$ hortorum (geranium), mixed basket including Calibrachoa spp. and Verbena spp.

Price for 30-cm basket

$\$ 12.99, \$ 13.99, \$ 14.99, \$ 15.99$

Insect management

Grown using: bee-friendly insect management, beneficial insects to control pests, no neonicotinoid insecticides, or traditional insect management

Indoor flowering plants in $10-\mathrm{cm}$ pots Species

Saintpaulia spp. (african violet), Hyacinthus spp. (hyacinth), Chrysanthemum (mum), Euphorbia pulcherrima (poinsettia)

Price for a $10-\mathrm{cm}$ pot $\$ 2.99, \$ 3.49, \$ 3.99, \$ 4.49$

Insect management

Grown using: bee-friendly insect management, beneficial insects to control pests, no neonicotinoid insecticides, or traditional insect management

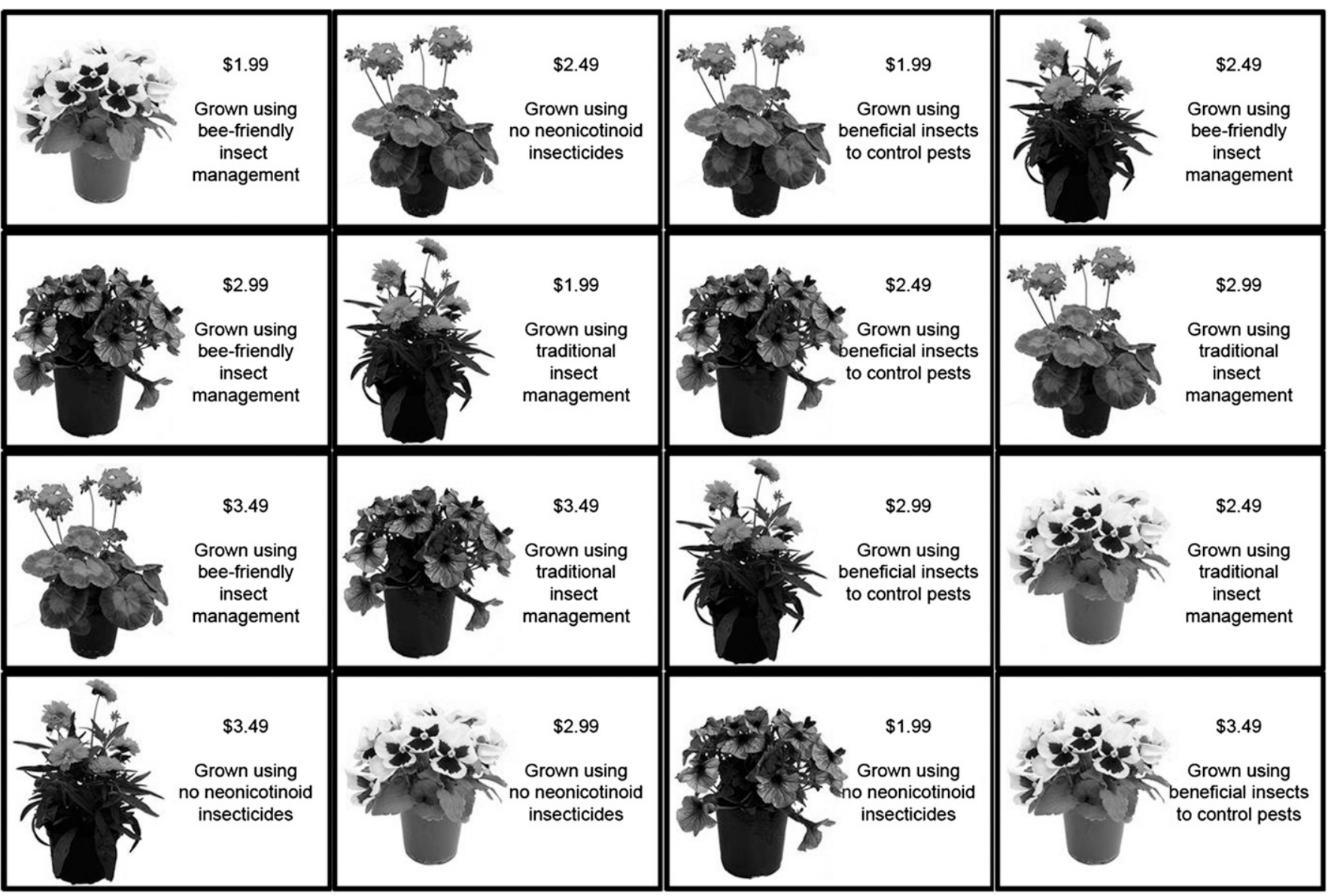

Fig. 1. First survey conjoint set, in order from left to right, top to bottom. Respondents were shown each picture individually in order and asked to rate each picture on a scale of 1 (very unlikely) to 5 (very likely) in terms of how likely they would be to purchase this flowering ornamental plant in a 10 -cm pot intended for use in the landscape at the given price and production method. 
(Provo, UT). Each survey was administered simultaneously and was active from 13 to 16 May 2014. Potential survey respondents were contacted from a pool maintained by Global Market Insite Institute [GMI (Bellevue, WA)] and invited to participate in the survey. Respondents were paid in points to redeem prizes through GMI.

Each survey collected measures of likeliness to buy and purchase and attitudinal measures. Each survey included a minimum of 1000 participants distributed across the continental United States with oversampling for three states: Oregon, Minnesota, and Michigan. Oregon and Minnesota were oversampled due to our specific interest in attitudes in those geographical areas because of greater incidences of media attention surrounding systemic insecticides' role in bee decline. In compliance with federal law, no participants below 18 years of age were invited to participate and the survey protocol and instrument were approved by the university's institutional review board for research involving human subjects (IRB no. x14-323e). The surveys included multiplechoice (single and multiple answer), freeform text entry, and rating (using a Likert scale) question types. With the exception of an initial consent-to-participate question, all survey questions were optional and respondents could choose to skip or choose to not answer any question. Questions were grouped into five categories: likelihood-tobuy, personal value orientations and environmental concerns, meaning of terms, purchasing habits, and demographic characteristics of the respondents.

All three surveys were identical for all questions, except for the likelihood-to-buy questions. Each likelihood-to-buy question was framed by showing a picture of the floriculture product with text of the price and a description of the greenhouse pest management production practices (Table 1). The consumer was then asked "How likely would you be to purchase this plant?" and asked to respond with a whole unit on the Likert scale of 1 (very unlikely) to 5 (very likely). The second set of questions (personal value orientations and environmental concerns) queried the importance of how major environmental issues impact their lives, society, and the world. The respondent was asked to rate their answer on a Likert 1 (not at all important) to 7 (extremely important) scale. The third block of questions (meaning of terminology) included five free-form text entry fields that asked the participant to describe their understanding of several production methods. In analyzing the five short answer questions for all participants, those with commonly stated phrases or terminology were grouped. Answers of each participant could be categorized in more than one of the emergent themes. The fourth block of questions (purchasing habits) asked the participant about their ornamental plant purchasing habits and what characteristics are important to them when purchasing. The final block of questions asked about the respondents' demographic information including age, gender, ethnicity, marital status, education, and household income.

Conjoint development. Conjoint analysis has frequently been used to understand the effects of product attributes and consumer characteristics on product choice decisions. For example, conjoint studies have been used as a means to elicit consumer preferences for a wide range of ornamental products, such as Christmas trees (Behe et al., 2005b), landscapes (Behe et al., 2005a; Zagaden et al., 2008), plant containers (Hall et al., 2010), and mixed flowering annual containers (Mason et al., 2008). Behe et al. (2013) used a conjoint design to identify nine consumer segments, focusing on their gardening purchases, and documented differences in consumer preferences for plant provenance and environmental attributes of transplants. The

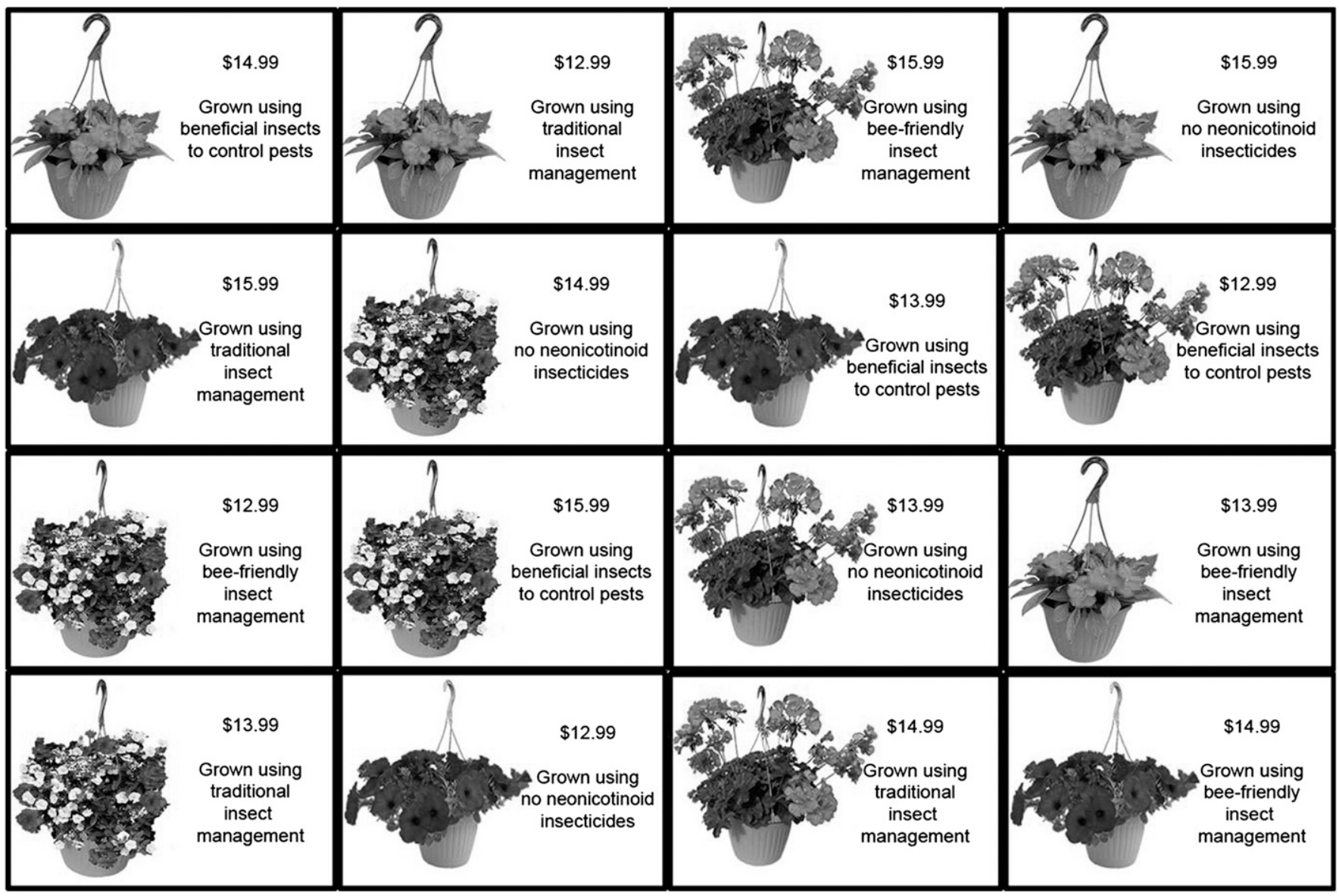

Fig. 2. Second survey conjoint set, in order from left to right, top to bottom. Respondents were shown each picture individually in order and asked to rate each picture on a scale of 1 (very unlikely) to 5 (very likely) in terms of how likely they would be to purchase this flowering ornamental plant in a 30 -cm hanging basket at the given price and production method. 
likelihood-to-buy questions framed in a conjoint design were developed to assess consumer response to three different product categories: indoor or outdoor flowering plants marketed in $10-\mathrm{cm}$ containers or outdoor flowering plants marketed in $30-\mathrm{cm}$ containers each with three attributes: species, price, and method of production. We used four different plant species in each category, with four prices, and four production practices (grown using bee-friendly insect management, grown using beneficial insects, grown using no neonicotinoid insecticides, and grown using traditional insect management; Table 1). The prices were chosen based on common price points for similar products in 2013.

Although all 64 permutations of attributes could have been presented to respondents, we developed partial factorial conjoint designs of 16 combinations of hypothetical ornamental plant products for each survey to reduce time investment (Chrzan and Orme, 2000) and respondent fatigue. Such a design is often used to improve experiment efficiency by using only a fraction of the attribute combinations in experiments while retaining the ability to assess all attributes in the complete design. We divided the plants of interest into three sets to further reduce the number of images each subject saw, further reducing the likelihood of fatigue. The first survey conjoint set queried images of flowering ornamental plants intended for use in an outdoor landscape in $10-\mathrm{cm}$ pots with a price and method of production (Fig. 1). The second survey conjoint set was identical, except it displayed flowering ornamental plants in $30-\mathrm{cm}$ hanging baskets with a price and method of production (Fig. 2). The third survey conjoint set displayed flowering ornamental plants intended for indoor use in $10-\mathrm{cm}$ pots also with a price and method of production (Fig. 3). For all three surveys, production practices were presented without definition or explanation and the images for the conjoint questions were shown to the participants before asking them any other questions. Species included in this study were chosen based on widely known and commonly available plants in the floriculture industry from images taken by the researchers or colleagues and used with their permission. Price points were chosen based on the market price of similar products in 2013. Methods of production were based on the researcher's observations of potential new marketing terminology.
Data analysis. Conjoint analysis is a statistical method used to determine preferences of participants for hypothetical products about a given set of attributes and was used here on the likelihood-to-buy questions (Kuhfeld, 2010). Conjoint analysis defines overall preference for a particular product, in this case ornamental plants with varying price points and production methods, as the sum of the part-worths (also termed utilities) for each factor level (Gaasbeck and Bouwman, 1991; Hartigan, 1975). In other words, the partworth utility shows the relative value of one level of an attribute to another whereas the relative importance shows the importance among attributes.

Conjoint analysis was conducted in SAS Version 9.3 (SAS Institute, Cary, NC) using PROC TRANSREG. Means of coefficients and relative importance across respondents were analyzed in PROC GLM for significant differences among attributes using Tukey's honestly significant test with $P=0.05$ as a maximum value of significance.Frequency data were analyzed for differences using Wilcoxon-MannWhitney (PROC NPAR1WAY). Likert scale questions were analyzed for differences using PROC GLM and comparisons were performed using least square means

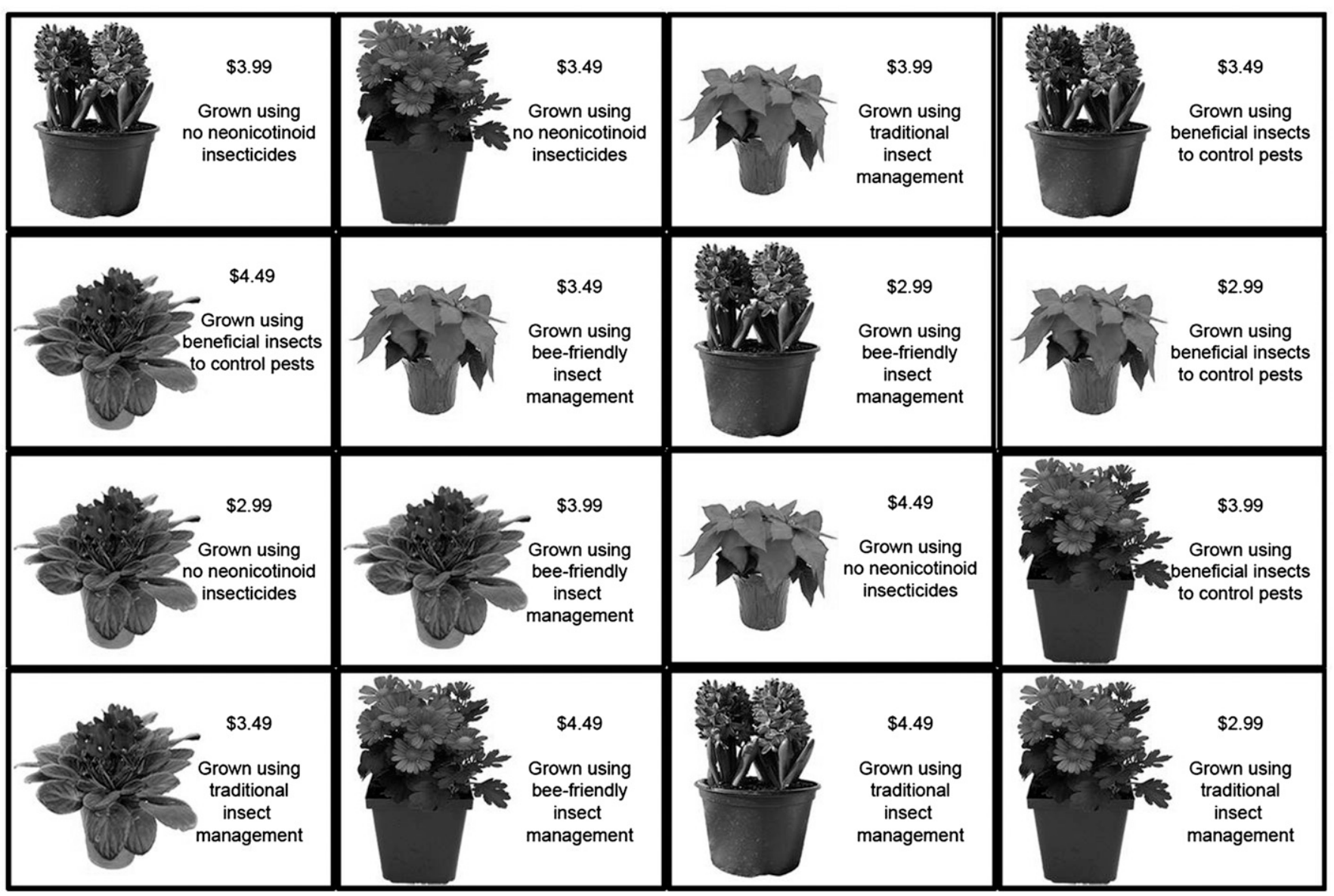

Fig. 3. Third survey conjoint set, in order from left to right, top to bottom. Respondents were shown each picture individually in order and asked to rate each picture on a scale of 1 (very unlikely) to 5 (very likely) in terms of how likely they would be to purchase this flowering ornamental plant in a 10-cm pot intended for indoor use at the given price and production method. 
with $P=0.05$ as a maximum value of significance.

\section{Results and Discussion}

Demographics. Demographic variables of the respondents (number of adults in the household, number of children below 18 years of age in the household, age, gender, ethnicity, highest level of education attained, area of residence, and household income), were generally homogenous and differed among only three characteristics (Table 2). One difference was that participants in the sample that viewed the outdoor flowering plants marketed in $10-\mathrm{cm}$ containers were, on average, 3 years older than the participants in the sample that viewed the hanging baskets and 4.1 years older than subjects in the sample viewing the indoor flowering plants (data not shown). Secondly, the sample that viewed the outdoor plants marketed in $10-\mathrm{cm}$ containers had $2.1 \%$ fewer persons of hispanic descent and $0.8 \%$ fewer than the sample that viewed the hanging baskets. Thirdly, the respondents to the survey showing outdoor flower- ing plants marketed in 10-cm containers was comprised of $15.7 \%$ more females than the persons who viewed the indoor flowering plants and $13.2 \%$ more than those who viewed the hanging baskets. Since the three samples were so similar demographically, they were combined where possible in subsequent analyses. Every state was represented in each sample with a few exceptions. For the indoor flowering plants, there were no subjects from North Dakota. For the outdoor $10-\mathrm{cm}$ containers, there were no subjects from Hawaii and Wyoming, whereas there were no respondents from Alaska, Hawaii, or North Dakota for the survey showing hanging baskets.

Purchasing habits. We queried participants on their plant purchases in the 12 months before the study. We compared the purchases of our sample to the percentage of households participating in the activity reported by the NGA (Butterfield and Baldwin, 2013). Purchases are a part of participation, but were the only known points of comparison available in the public realm. Of the total participants, $65.1 \%(n=2002)$ of the subjects had purchased an annual

Table 2. Pooled demographical characteristics of participants in three Internet surveys that assessed consumer willingness to pay for different pest control practices.

\begin{tabular}{|c|c|}
\hline Demographics & Mean counts (SE) or frequency (\%) \\
\hline$\overline{\mathrm{N}}$ & 3,082 \\
\hline Adults in household ${ }^{\mathrm{z}}$ & $1.34(0.0178)$ \\
\hline Children in household ${ }^{z}$ & $0.5(0.0171)$ \\
\hline Age (years; at the time of survey) ${ }^{\mathrm{z}}$ & $53.43(0.2669)$ \\
\hline \multicolumn{2}{|l|}{ Gender $^{y}$} \\
\hline Female & $1,698(55.3 \%)$ \\
\hline Male & $1,375(44.7 \%)$ \\
\hline \multicolumn{2}{|l|}{ Ethnicity ${ }^{y}$} \\
\hline African American & $182(5.7 \%)$ \\
\hline Asian & $115(3.6 \%)$ \\
\hline Hispanic & $123(3.9 \%)$ \\
\hline Native American & $43(1.4 \%)$ \\
\hline Pacific Islander & $9(0.3 \%)$ \\
\hline White/Caucasian & $2,680(84.4 \%)$ \\
\hline Other & $24(0.8 \%)$ \\
\hline \multicolumn{2}{|l|}{ Education $^{\mathrm{y}}$} \\
\hline Less than high school & $35(1.1 \%)$ \\
\hline High school/GED & $538(17.5 \%)$ \\
\hline Some college & $731(23.8 \%)$ \\
\hline 2-year college degree & $381(12.4 \%)$ \\
\hline 4-year college degree & $926(30.1 \%)$ \\
\hline Master's degree & $372(12.1 \%)$ \\
\hline Professional degree (JD, MD) & $60(2 \%)$ \\
\hline Doctoral degree & $32(1 \%)$ \\
\hline \multicolumn{2}{|l|}{ Area $^{y}$} \\
\hline Metropolitan region & $663(22.2 \%)$ \\
\hline Rural region & $702(23.5 \%)$ \\
\hline Suburban region & $1,621(54.3 \%)$ \\
\hline \multicolumn{2}{|l|}{ Income $\mathrm{y}^{\mathrm{y}}$} \\
\hline Less than $\$ 19,999$ & $396(13 \%)$ \\
\hline$\$ 20,000-\$ 39,999$ & $622(20.4 \%)$ \\
\hline$\$ 40,000-\$ 59,999$ & $597(19.5 \%)$ \\
\hline$\$ 60,000-\$ 79,999$ & $540(17.7 \%)$ \\
\hline$\$ 80,000-\$ 99,999$ & $340(11.1 \%)$ \\
\hline$\$ 100,000-\$ 119,999$ & $199(6.5 \%)$ \\
\hline$\$ 120,000-\$ 139,999$ & $111(3.6 \%)$ \\
\hline$\$ 140,000-\$ 159,999$ & $101(3.3 \%)$ \\
\hline$\$ 160,000-\$ 179,999$ & $42(1.4 \%)$ \\
\hline$\$ 180,000-\$ 199,999$ & $45(1.5 \%)$ \\
\hline$\$ 200,000$ or more & $64(2.1 \%)$ \\
\hline
\end{tabular}

${ }^{\mathrm{z}}$ Mean (SE).

${ }^{\mathrm{y}}$ Frequency $(\%)$.

flowering plant in the 12 months before the survey (Table 3 ). The NGA reported that $31 \%$ of U.S. households participated in flowering gardening with average expenditures of $\$ 68$ per household. A total of $37.3 \%$ of our sample had purchased flowering perennials compared with $18.7 \%$ of the NGA sample. Indoor flowering and foliage plants were purchased by $24.3 \%$ and $27.5 \%$ of our sample but not reported in the NGA study.

Of our sample, $59.1 \%$ had made any horticultural product or plant purchase from a home improvement or hardware store, $44.7 \%$ from an independent, freestanding garden center, $30.5 \%$ from a mass-merchandiser, $22.1 \%$ from a supermarket or grocery store, $7.4 \%$ online, and $3.1 \%$ from a print catalog. When asked where most of their gardening-related purchases were made, $59.1 \%$ reported the home improvement or hardware store, $44.7 \%$ independent, free-standing garden center, $30.5 \%$ mass-merchandiser, $22.1 \%$ supermarket or grocery store, $7.4 \%$ online, and $3.1 \%$ print catalog.

Knowledge of pest control terminology. Of all participants who described their understanding of each of the four production methods in a free-form question, 34.9\% believed correctly that "bee-friendly" meant that the pest management is not harmful to bees. Almost a fifth $(18.8 \%)$ believed that "bee-friendly" meant a plant was attractive to bees (Table 4). Respondents seem to be confusing the plant production practice vs. the plant itself (as a pollinator food source) as bee-friendly. However, when participants were given numerous choices about the meaning of "bee-friendly" practices, the majority of participants $(66.8 \%)$ accurately identified that "bee-friendly" practices do not harm bees (see Table 7, described later). In contrast, over half $(56.6 \%)$ of all participants reported that they did not understand the term "neonicotinoid-free" and $10.5 \%$ believed that those plants were not treated with any insecticide when describing the term in a free-form question. When participants were rating (from one to six) their knowledge of neonicotinoid-free practices, $69.9 \%$ identified themselves as not understanding the production type (data not shown). This indicates that consumers who did not understand "neonicotinoidfree" may have left the free-from question blank or typed another answer that did not readily fit into any category. Similarly, in a separate study, a relatively low percentage of attendees at Midwest Home and Garden shows were able to identify terminology associated with integrated pest management (IPM) such as pest tolerance $(16 \%)$, pest scouting $(19 \%)$, or organic farming (11\%) (Klingeman et al., 2004). The relatively low understanding of pest control terminology among the general public may be a source of confusion when labeling plants with pest control practices used during production, especially those containing compound names such as 
Table 3. The type of plant purchased and the types of stores in which plants were bought by participants who had purchased an ornamental plant in the last 12 months for all surveys combined.

\begin{tabular}{lc}
\hline Plant purchases in last 12 mo. & Frequency (\%) \\
\hline $\mathrm{N}$ & $2,002(65.1 \%)$ \\
Type of plant purchased in past 12 months (select all that apply) & \\
Annual flowering plants (e.g., petunia, marigold, impatiens). & $1,259(62.9 \%)$ \\
Evergreen trees or shrubs (e.g., pines, conifers, junipers) & $189(9.4 \%)$ \\
Flowering perennials (e.g., hosta, chrysanthemum, day lily, cone flower) & $747(37.3 \%)$ \\
Flowering shrubs (hydrangea, liliac, etc.) & $413(20.6 \%)$ \\
Fruit producing trees (apple, pear, etc.) & $215(10.7 \%)$ \\
Herbs (e.g., basil, parsley, sage) & $626(31.3 \%)$ \\
Indoor flowering potted plants (e.g., orchid, african violet, etc.) & $487(24.3 \%)$ \\
Indoor foliage plants (e.g., ferns, spider plant, pothos) & $550(27.5 \%)$ \\
Non-flowering shrubs (e.g., boxwood, taxus, etc.) & $172(8.60 \%)$ \\
Shade trees (e.g., maple, oak, etc.) & $123(6.1 \%)$ \\
Vegetable plants (e.g., tomato, pepper) & $967(48.3 \%)$ \\
Type of store purchased from (select all that apply) & \\
Home improvement or hardware store & $1,183(59.1 \%)$ \\
Independent, free-standing garden center & $895(44.7 \%)$ \\
Internet & $149(7.4 \%)$ \\
Mass-merchandiser & $611(30.5 \%)$ \\
None of the above & $54(2.7 \%)$ \\
Print catalog & $63(3.1 \%)$ \\
Supermarket or grocery store & $443(22.1 \%)$ \\
Type of store made MOST purchases from (select only one) & \\
Home improvement store & $805(40.2 \%)$ \\
Independent, free-standing garden center & $610(30.5 \%)$ \\
Internet & $52(2.6 \%)$ \\
Mass-merchandiser & $307(15.3 \%)$ \\
None of the above & $57(2.8 \%)$ \\
Print catalog & $25(1.2 \%)$ \\
Supermarket or grocery store & $139(6.9 \%)$ \\
\hline
\end{tabular}

neonicotinoid. Forty-eight percent of participants reported that "traditional" insect management was pest control using insecticides or pesticides (Table 4). The pest control practice "plants grown with beneficial insects" elicited a positive response from $44.9 \%$ of survey respondents and $40.6 \%$ provided the definition that it uses a pest's natural enemy to reduce the pest population.

We then tested to see whether those respondents that stated that they were "extremely knowledgeable" or "moderately knowledgeable" (Know) had a greater understanding of the stated production practice compared with the respondents who characterized themselves as "Not at all knowledgeable" or have "Never heard of this" (Do not know). Respondents who said that they understood the term "bee-friendly" were more likely to describe it as plants not treated with any chemicals or pesticides or that "beefriendly" production practices protect the bee population (Table 4). Survey participants who knew the term "neonicotinoid-free" were more likely to state that the production practice was not harmful to bees, non-toxic, or natural compared with those who said that they did not know the term "neonicotinoidfree." Respondents identifying themselves as understanding the term pest control with "beneficial insects" were more likely to have a positive response or describe it as insects eating other insects, natural, organic, or to give an example of the lady bug as compared with those who did not.

Important factors when purchasing plants. Unlike the stated preferences for attitudinal and knowledge variables, conjoint analysis extracts the relative importance of each attribute and level from the implied preference. The relative importance and part-worth utility for each attribute (price, production type, and plant species) in each of the three conjoint studies are shown in Table 5. The part-worth utility was used to examine the order of importance of these factors to the respondents within each survey. For those who viewed the indoor $10-\mathrm{cm}$ flowering plants, the plant species accounted for $41.2 \%$ of the decision to purchase the plant, followed by production type $(32.8 \%)$ and price $(26.0 \%)$. All three product attributes were of equal importance to the subjects who viewed the outdoor $10-\mathrm{cm}$ flowering plants. For those who viewed the $30-\mathrm{cm}$ hanging baskets, price had a lower relative importance compared with production type and species. In contrast, consumer preferences of $403 \mathrm{Ca}$ nadian consumers buying greenhousegrown chrysanthemums valued price $(22 \%$ to $29 \%$ relative importance) over pest management ( $22 \%$ to $25 \%$ relative importance) (Grygorczyk et al., 2014).

Across all three surveys, lower prices were preferred to higher prices. While this may seem intuitive, this indicates the use of logic or rational reasoning by subjects when coming to a conclusion about their willingness to purchase the plants shown in the images. Among the four insect control methods, the "traditional" insect control method was preferred least (had a lower part-worth score) in each of the three conjoint studies compared with the other methods. In fact, "traditional" insect control was heavily discounted as indicated by the part-worth score. The term "beefriendly" had a higher part-worth utility score (meaning it was more valuable to survey participants) compared with the "use of beneficial insects" or "no use of neonicotinoids" across all three conjoint samples.

Participants in the outdoor $10-\mathrm{cm}$ and $30-\mathrm{cm}$ hanging baskets surveys valued the terms "beneficial insects" and "no use of neonicotinoids" differently compared with those participant in the indoor $10-\mathrm{cm}$ plant survey. The subjects who viewed the indoor flowering plants discounted "traditional" insect control. For the subjects who viewed the outdoor $10-\mathrm{cm}$ flowering plants or the 30-cm hanging baskets, "bee-friendly" and "use of beneficial insects" had positive partworth utility scores, but "neonicotinoidfree" and "traditional insect control" both had negative part-worth utility scores. Therefore, the term "neonicotinoid-free" was not as valuable for outdoor plants as for indoor plants, which is counterintuitive since the concern about effects of systemic insecticides on pollinators is only relevant outdoors (there are no pollinators indoors). We infer from these findings that the sample was more concerned about their exposure to pesticides than pollinator's exposure, especially when the majority does not understand what neonicotinoid insecticides are. Furthermore, respondents placed more value on the term "bee-friendly" or "using beneficial insects" than "not using neonicotinoids." We conclude from these findings that the use of the term "bee-friendly" will bring the greatest return or value to the retailer because it had the greatest partworth utility score.

To put these results into context, the difference between the lowest and the highest price was $\$ 1.50$ for both the indoor and outdoor $10-\mathrm{cm}$ plants and $\$ 3.00$ for the $30-\mathrm{cm}$ hanging basket. The price utility difference for the indoor $10-\mathrm{cm}$ plants, outdoor $10-\mathrm{cm}$ plants, and $30-\mathrm{cm}$ hanging baskets were $0.408,0.736$, and 0.392 , respectively. Therefore, the change in the part-worth means score was worth $\$ 3.69$ for respondents who viewed the indoor $10-\mathrm{cm}$ plants and $\$ 2.04$ for the respondents who viewed the outdoor $10-\mathrm{cm}$ plants. The change in partworth utility score for the people who viewed the $30-\mathrm{cm}$ hanging baskets was $\$ 7.65$. For the consumers who viewed the $10-\mathrm{cm}$ indoor plants, we can conclude that "bee-friendly" is worth $\$ 0.17, \$ 0.13$, or $\$ 1.01$ more than plants labeled with "grown with beneficial insects," "neonicotinoid-free" or "grown with traditional control," respectively. Similarly, respondents who viewed the 10 -cm outdoor plant survey valued "bee-friendly" $\$ 0.15, \$ 0.45$, or $\$ 0.96$ more than "grown with beneficial insects," "neonicotinoid-free" or "grown with traditional control" pest control practices, respectively. Some of the greatest price premiums for "bee-friendly" practices were for a $30-\mathrm{cm}$ hanging baskets; 
Table 4. The frequency of written attributes as described in a free-hand question of pest control by bee-friendly, neonicotinoid-free, traditional, or pest control with beneficial insects. Means within a column followed by the same capital letter are not different at the $P<0.05$ level based on multiple paired $t$ tests. Means within a row followed by the same lower case letter are not different at the $P<0.05$ level based on Tukey's honestly significant difference test.

\begin{tabular}{|c|c|c|c|c|c|}
\hline \multirow[b]{2}{*}{ Terminology } & \multirow[b]{2}{*}{ Meaning of terminology to participants } & \multirow{2}{*}{$\begin{array}{l}\text { Frequency of participants } \\
\text { holding belief }(\%)\end{array}$} & \multirow[b]{2}{*}{ Mean (SE) } & \multicolumn{2}{|c|}{ Mean of } \\
\hline & & & & Know $^{z}$ & Not know ${ }^{\mathrm{y}}$ \\
\hline \multirow[t]{9}{*}{ Bee-friendly } & & & & $\mathrm{n}=553$ & $\mathrm{n}=1,078$ \\
\hline & Plants not harmful to the bees & $1,077(34.9 \%)$ & $0.35(0.0086) \mathrm{A}$ & $0.33(0.0200) \mathrm{a}$ & $0.31(0.0141) \mathrm{a}$ \\
\hline & Plants attracts bees & $579(18.8 \%)$ & $0.19(0.0070) \mathrm{B}$ & $0.17(0.0161) \mathrm{a}$ & $0.19(0.0120) \mathrm{a}$ \\
\hline & Bees able to pollinate & $540(17.5 \%)$ & $0.18(0.0068) \mathrm{B}$ & $0.16(0.0156) \mathrm{a}$ & $0.15(0.0109) \mathrm{a}$ \\
\hline & Not grown with harmful pesticides & $345(11.2 \%)$ & $0.11(0.0056) \mathrm{C}$ & $0.10(0.0125) \mathrm{a}$ & $0.08(0.0083) \mathrm{a}$ \\
\hline & Do not know & $321(10.4 \%)$ & $0.10(0.0055) \mathrm{C}$ & $0.06(0.0101) \mathrm{b}$ & $0.19(0.0120) \mathrm{a}$ \\
\hline & Plants will not kill the bees & $260(8.4 \%)$ & $0.08(0.0050) \mathrm{D}$ & $0.09(0.0120) \mathrm{a}$ & $0.07(0.0076) \mathrm{a}$ \\
\hline & Not Tteated with any chemicals or pesticides & $173(5.6 \%)$ & $0.06(0.0041) \mathrm{E}$ & $0.06(0.0104) \mathrm{a}$ & $0.04(0.0058) \mathrm{b}$ \\
\hline & Protects bee population & $116(3.8 \%)$ & $0.04(0.0034) \mathrm{F}$ & $0.05(0.0095) \mathrm{a}$ & $0.02(0.0043) \mathrm{b}$ \\
\hline \multirow[t]{12}{*}{ Neonicotinoid free } & & & & $\mathrm{n}=255$ & $\mathrm{n}=2,113$ \\
\hline & Do not know & $1,745(56.6 \%)$ & $0.57(0.0089) \mathrm{A}$ & $0.27(0.0277) \mathrm{b}$ & $0.69(0.0101) \mathrm{a}$ \\
\hline & Plants not treated with any insecticide & $325(10.5 \%)$ & $0.11(0.0055) \mathrm{B}$ & $0.11(0.0196) \mathrm{a}$ & $0.10(0.0065) \mathrm{a}$ \\
\hline & Nicotine-based chemical not used on plants & $178(5.8 \%)$ & $0.06(0.0042) \mathrm{C}$ & $0.07(0.0165) \mathrm{a}$ & $0.03(0.0039) \mathrm{b}$ \\
\hline & Not harmful to bees & $174(5.6 \%)$ & $0.06(0.0041) \mathrm{C}$ & $0.10(0.0190) \mathrm{a}$ & $0.03(0.0035) \mathrm{b}$ \\
\hline & Not using harmful or toxic insecticides & $97(3.1 \%)$ & $0.03(0.0031) \mathrm{D}$ & $0.05(0.0143) \mathrm{a}$ & $0.02(0.0032) \mathrm{b}$ \\
\hline & Non-toxic & $51(1.7 \%)$ & $0.01(0.0022) \mathrm{E}$ & $0.04(0.0116) \mathrm{a}$ & $0.01(0.0023) \mathrm{b}$ \\
\hline & Safe & $42(1.3 \%)$ & $0.01(0.0020) \mathrm{E}$ & $0.02(0.0078) \mathrm{a}$ & $0.01(0.0026) \mathrm{a}$ \\
\hline & Only use less harmful insecticides & $43(1.4 \%)$ & $0.01(0.0021) \mathrm{E}$ & $0.01(0.0055) \mathrm{a}$ & $0.01(0.0022) \mathrm{a}$ \\
\hline & Natural & $30(0.97 \%)$ & $0.01(0.0019) \mathrm{E}$ & $0.04(0.0116) \mathrm{a}$ & $0.01(0.0016) \mathrm{b}$ \\
\hline & Environmentally friendly & $28(0.91 \%)$ & $0.01(0.0017) \mathrm{E}$ & $0.01(0.0055) \mathrm{a}$ & $0.01(0.0018) \mathrm{a}$ \\
\hline & Does not cause colony collapse disorder (CCD) & $20(0.65 \%)$ & $0.01(0.0013) \mathrm{E}$ & $0.02(0.0078) \mathrm{a}$ & $0.00(0.0011) b$ \\
\hline \multirow[t]{9}{*}{ Traditional } & & & & $\mathrm{n} / \mathrm{a}$ & $\mathrm{n} / \mathrm{a}$ \\
\hline & Use of a chemical, insecticide, or pesticide spray & $1,496(48.5 \%)$ & $0.48(0.0090) \mathrm{A}$ & & \\
\hline & Do not know & $522(16.9 \%)$ & $0.17(0.0067) \mathrm{B}$ & & \\
\hline & Negative response & $455(14.8 \%)$ & $0.16(0.0064) \mathrm{C}$ & & \\
\hline & Harmful & $304(9.9 \%)$ & $0.10(0.0053) \mathrm{D}$ & & \\
\hline & Usual methods; not defined & $274(8.9 \%)$ & $0.09(0.0052) \mathrm{D}$ & & \\
\hline & Positive response & $275(8.9 \%)$ & $0.09(0.0052) \mathrm{D}$ & & \\
\hline & Insect control without chemical control & $207(6.7 \%)$ & $0.07(0.0045) \mathrm{E}$ & & \\
\hline & Poison or toxic & $131(4.3 \%)$ & $0.04(0.0036) \mathrm{F}$ & & \\
\hline \multirow[t]{10}{*}{ Beneficial insects } & & & & $\mathrm{n}=585$ & $\mathrm{n}=1,121$ \\
\hline & Positive response & $1,383(44.9 \%)$ & $0.45(0.0089) \mathrm{A}$ & $0.53(0.0207) \mathrm{a}$ & $0.32(0.0140) \mathrm{b}$ \\
\hline & Insects eating other insects; correct basic & & & & \\
\hline & definition of biological control & $1,256(40.6 \%)$ & $0.41(0.0088) \mathrm{B}$ & $0.42(0.0204) \mathrm{a}$ & $0.29(0.0136) b$ \\
\hline & Do not know & $779(25.2 \%)$ & $0.25(0.0078) \mathrm{C}$ & $0.16(0.0153) \mathrm{b}$ & $0.43(0.0148) \mathrm{a}$ \\
\hline & Natural & $234(7.6 \%)$ & $0.08(0.0047) \mathrm{D}$ & $0.08(0.0112) \mathrm{a}$ & $0.05(0.0067) b$ \\
\hline & No pesticide use & $198(6.4 \%)$ & $0.06(0.0044) \mathrm{DE}$ & $0.06(0.0097) \mathrm{a}$ & $0.05(0.0064) \mathrm{a}$ \\
\hline & Give example of Lady Bug & $186(6.0 \%)$ & $0.06(0.0042) \mathrm{E}$ & $0.11(0.0129) \mathrm{a}$ & $0.02(0.0041) b$ \\
\hline & Environmentally-friendly & $92(3.0 \%)$ & $0.03(0.0030) \mathrm{F}$ & $0.02(0.0063) \mathrm{a}$ & $0.02(0.0044) \mathrm{a}$ \\
\hline & Organic & $15(0.49 \%)$ & $0.01(0.0018) \mathrm{G}$ & $0.01(0.0042) \mathrm{a}$ & $0.00(0.0015) \mathrm{b}$ \\
\hline
\end{tabular}

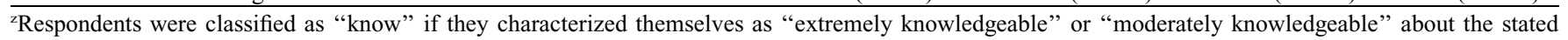
production practice.

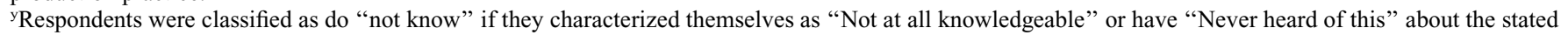

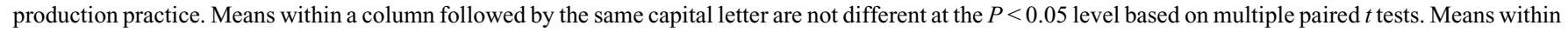
a row followed by the same lower case letter are not different at the $P<0.05$ level based on Tukey's honestly significant difference test.

consumers valued "bee-friendly" \$0.53, $\$ 1.48$, or $\$ 2.10$ more than pest management with beneficial insects, without neonicotinoids, or with traditional control, respectively.

Among the indoor plants, african violets were preferred similarly high compared with hyacinths, with chrysanthemums preferred less than african violets. Poinsettias were the least preferred indoor flowering plant compared with the three others, with the lowest part-worth utility score. Among the $10-\mathrm{cm}$ outdoor flowering plants, petunias were most preferred, followed by pansies, and then more than both geranium and coreopsis. Among the $30-\mathrm{cm}$ flowering hanging basket, the petunia was most preferred followed by the mixed container, new guinea impatiens, and geranium. While including different plants helped replicate the task, we were not as concerned with plant preferences as we were with pest management. However, we acknowledge that poinsettia sales have declined over the past decades, indicative of a declining market and, perhaps, consumer disinterest as we report here.

Plant purchaser vs. non plant purchaser. Knowledge. Participants were divided into two groups for the remainder of the analysis: those that had purchased ornamental plants in the 12 months before the survey and those who had not. When participants were queried about their knowledge about different aspects of pest control, those who had purchased an ornamental plant in the 12 months prior consistently had a greater percentage of self-reported knowledge compared with those that had not bought a plant in the last 12 months (Table 6).

The 19 listed characteristics of "beefriendly" plant production were compared between the plant purchasers and the nonplant purchasers (Table 7). The percentage of participants considering "bee-friendly" plant production differed for 15 of the 19 characteristics between the plant purchasers and the people who had not purchased a plant in the last 12 months. Consistently, the percentage of participants who agreed that the characteristic was a part of "bee-friendly" production was greater for those who had purchased an ornamental plant in the 12 months before the study with one exception: "I do not know what bee-friendly production is." Three of the listed characteristics could be classified as negative: "expensive," "higher price," or "marketing gimmick." Of these, a similar percentage of consumers agreed that "beefriendly" production practices were a marketing gimmick. The other similarities were for "pesticides are used," "plants are not attractive to bees," and "some other characteristic not listed." In many instances, $>20 \%$ more of the sample who had 
purchased ornamental plants in the 12 months before the study found the stated characteristic consistent with "bee-friendly" production. This may indicate that the ornamental plant purchasers have a heightened awareness of what constitutes "beefriendly" production compared with the general public.

Importance of production practices. We then split the survey respondents into those that have purchased an ornamental plant in the 12 months before the survey with those who had not to see if there was a difference in their knowledge or preferences for pest control (Table 8). In all cases, the stated importance of each characteristic was higher for those who had purchased an ornamental plant compared with those who had not. Yet the ranking of order of importance was similar across both samples. Respondents in our study reported that the most important factor was that the flowering plant has no plant damage. Similarly, multiple surveys demonstrate that consumers may be willing to pay a premium for organically grown but still expect a similar quality to the conventionally managed crops (Jetter and Paine, 2004; Ott, 1990; Olson et al., 1995; Thompson and Kidwell, 1998; Wells et al., 1994). The second most important factor in our study was that the "plants have no insects on them" whereas the third most important factor was that the "flowering plants have no pesticide residue on or in the plant leaves." "No pesticide residue on or in the flowers" was the fourth most important factor followed by that the "plant be produced using bee-friendly production practices." Last in the ranking of stated importance was that "no neonicotinoids were used during the production of the plant." Our results are consistent with popularly held belief that customers perceive that any presence of insects, beneficial or not, reduces the quality of plants (Marsh and Gallardo, 2009).

We also investigated respondents' attitude about pesticide use by asking them to use a 7-point Likert scale when reporting their level of agreement to 7 variables (Table 9). We had a higher level of agreement for six of the seven variables among those who had purchased an ornamental plant in the 12 months before the study. The samples were similar with their level of agreement to the statement, "All pesticides are harmful." With a midpoint on the scale of 3.5 , there was general agreement among both samples with the other six statements. However, in each case there was a greater level of agreement with each statement among those who had purchased an ornamental plant in the 12 months before the study. All respondents most strongly agreed that they do not want any pesticide residues on their landscape plants followed by "I would tolerate some pesticide residue on flowering plants if the pesticides controlled invasive pests." These data contrast with previous findings reported in Table 8, where respondents 
Table 6. Knowledge. Respondents who have purchased an ornamental plant in past 12 months and those who have not purchased an ornamental plant in past 12 months knowledge about pest management practices on a scale of 1 (Never heard of this) to 6 (Extremely knowledgeable). Differences between the plant purchaser and the non-plant purchaser across rows was determined by using least square means with $P=0.05$ as a maximum value of significance.

\begin{tabular}{|c|c|c|c|}
\hline \multirow[b]{2}{*}{ Topic } & \multicolumn{3}{|c|}{ Mean (SE) } \\
\hline & $\begin{array}{l}\text { Have NOT purchased an ornamental } \\
\text { plant in past } 12 \mathrm{mo} .\end{array}$ & $\begin{array}{l}\text { Have purchased an ornamental } \\
\text { plant in past } 12 \text { mo. }\end{array}$ & Total \\
\hline Biological control agents & $2.41(0.0355) \mathrm{a}$ & $2.97(0.0306) \mathrm{b}$ & $2.78(0.0239)$ \\
\hline Grown bee friendly & $2.69(0.0372) \mathrm{a}$ & $3.41(0.0301) \mathrm{b}$ & $3.16(0.0243)$ \\
\hline Grown with beneficial insects & $2.67(0.0383) \mathrm{a}$ & $3.4(0.0302) b$ & $3.15(0.0246)$ \\
\hline Imidacloprid-free production & $1.86(0.0332) \mathrm{a}$ & $2.15(0.0302) \mathrm{b}$ & $2.05(0.0229)$ \\
\hline Insecticide-free production & $2.67(0.0357) \mathrm{a}$ & $3.37(0.0277) b$ & $3.13(0.0227)$ \\
\hline Integrated pest management (IPM) & $2.28(0.0362) \mathrm{a}$ & $2.84(0.0313) b$ & $2.65(0.0244)$ \\
\hline Invasive pests & $2.65(0.0394) \mathrm{a}$ & $3.32(0.0313) b$ & $3.09(0.0252)$ \\
\hline Neonicotinoid-free production & $2.01(0.0347) \mathrm{a}$ & $2.38(0.0308) b$ & $2.26(0.0236)$ \\
\hline Pest control using pest's natural enemies & $2.88(0.0388) \mathrm{a}$ & $3.55(0.0291) \mathrm{b}$ & $3.32(0.0240)$ \\
\hline Pesticide-free production & $2.87(0.0374) \mathrm{a}$ & $3.61(0.0279) \mathrm{b}$ & $3.35(0.0232)$ \\
\hline Pyrethroid-free production & $1.97(0.0344) \mathrm{a}$ & $2.39(0.0313) b$ & $2.24(0.0239)$ \\
\hline Sustainable production & $2.75(0.0372) \mathrm{a}$ & $3.45(0.0295) b$ & $3.21(0.0239)$ \\
\hline
\end{tabular}

Table 7. The frequency of characteristics of bee-friendly plant production between participants who have and have not purchased an ornamental plant in past 12 months. Comparisons between those who have and have not purchased plants in the past 12 months for each characteristic shown by lower case letters in rows determined by Wilcoxon-Mann-Whitney.

\begin{tabular}{|c|c|c|c|}
\hline \multirow[b]{2}{*}{ Characteristic } & \multicolumn{3}{|c|}{ Frequency $(\%)$} \\
\hline & $\begin{array}{l}\text { Have NOT purchased an ornamental } \\
\text { plant in past } 12 \mathrm{mo} .\end{array}$ & $\begin{array}{l}\text { Have purchased an ornamental } \\
\text { plant in past } 12 \text { mo. }\end{array}$ & Total \\
\hline Bees are not harmed & $618(57.2 \%) \mathrm{a}$ & $1,436(71.7 \%) b$ & $2,058(66.8 \%)$ \\
\hline Better for the environment & $416(38.5 \%) \mathrm{a}$ & $1,087(54.3 \%) b$ & $1,508(48.9 \%)$ \\
\hline Environmentally friendly & $405(37.5 \%) \mathrm{a}$ & $1,051(52.5 \%) \mathrm{b}$ & $1,460(47.4 \%)$ \\
\hline Use of products without bee toxicity & $414(38.3 \%) \mathrm{a}$ & $1,004(50.1 \%) b$ & $1,420(46.1 \%)$ \\
\hline Safer for humans & $295(27.3 \%) \mathrm{a}$ & $860(43 \%) b$ & $1,158(37.6 \%)$ \\
\hline Use of natural products & $289(26.8 \%) \mathrm{a}$ & $769(38.4 \%) b$ & $1,061(34.4)$ \\
\hline Pesticides are not used & $287(26.6 \%) \mathrm{a}$ & $709(35.4 \%) b$ & $998(32.4 \%)$ \\
\hline Insecticides are not used & $247(22.9 \%) \mathrm{a}$ & $632(31.6 \%) b$ & $882(28.6 \%)$ \\
\hline Less pesticide residue on products & $230(21.3 \%) \mathrm{a}$ & $601(30 \%) b$ & $832(27 \%)$ \\
\hline Use of natural pesticides & $214(19.8 \%)$ a & $568(28.4 \%) b$ & $783(25.4 \%)$ \\
\hline No synthetic pesticide use & $173(16 \%) \mathrm{a}$ & $451(22.5 \%) b$ & $625(20.3 \%)$ \\
\hline I do not know what bee-friendly production is & $290(26.9 \%) b$ & $262(13.1 \%) \mathrm{a}$ & $553(17.9 \%)$ \\
\hline Higher price & $116(10.7 \%) \mathrm{a}$ & $317(15.8 \%) b$ & $433(14 \%)$ \\
\hline Use of biopesticides & $89(8.2 \%) \mathrm{a}$ & $281(14 \%) b$ & $370(12 \%)$ \\
\hline Expensive & $58(5.4 \%) \mathrm{a}$ & $181(9 \%) b$ & $240(7.8 \%)$ \\
\hline Plants not attractive to bees & $35(3.2 \%) \mathrm{a}$ & $88(4.4 \%) \mathrm{a}$ & $125(4.1)$ \\
\hline Some other characteristic not listed & $42(3.9 \%) \mathrm{a}$ & $52(2.6 \%) \mathrm{a}$ & $95(3.1 \%)$ \\
\hline Marketing gimmick & $35(3.2 \%) \mathrm{a}$ & $57(2.8 \%) \mathrm{a}$ & $92(3 \%)$ \\
\hline Pesticides are used & $21(1.9 \%) \mathrm{a}$ & $69(3.4 \%) \mathrm{a}$ & $91(3 \%)$ \\
\hline
\end{tabular}

Table 8. Respondents were asked the importance of numerous factors influencing their purchase decision on a scale of 1 (Not at all important) to 7 (Very important). Comparisons between those who have purchased an ornamental plant in the past 12 months vs. those who have not purchased an ornamental plant in the past 12 months are in lower case letters in rows determined by using least square means with $P=0.05$ as a maximum value of significance.

\begin{tabular}{|c|c|c|c|}
\hline \multirow[b]{2}{*}{ Characteristic } & \multicolumn{3}{|c|}{ Mean (SE) } \\
\hline & $\begin{array}{l}\text { Have NOT purchased an } \\
\text { ornamental plant in past } 12 \text { mo. }\end{array}$ & $\begin{array}{c}\text { Have purchased an } \\
\text { ornamental plant in past } 12 \text { mo. }\end{array}$ & Total \\
\hline No neonicotinoid products were used during production of the plant & $3.82(0.0564) \mathrm{b}$ & $4.05(0.0433) \mathrm{a}$ & $4(0.0344)$ \\
\hline $\begin{array}{l}\text { Pest insects were controlled by using beneficial insects during the } \\
\text { production of this plant }\end{array}$ & $4.26(0.0573) b$ & $4.44(0.0427) \mathrm{a}$ & $4.4(0.0342)$ \\
\hline The flowering plant has no pesticide residue on or in the flowers & $4.57(0.0594) \mathrm{b}$ & $4.85(0.0430) \mathrm{a}$ & $4.8(0.0349)$ \\
\hline The flowering plant has no pesticide residue on or in the plant leaves & $4.82(0.0595) \mathrm{b}$ & $5.19(0.0415) \mathrm{a}$ & $5.1(0.0341)$ \\
\hline The flowering plant has very little plant damage & $5.10(0.0563) \mathrm{b}$ & $5.85(0.0321) \mathrm{a}$ & $5.6(0.0294)$ \\
\hline The flowering plant was produced with as little pesticides as possible & $4.64(0.0575) \mathrm{b}$ & $4.89(0.0424) \mathrm{a}$ & $4.8(0.0341)$ \\
\hline The flowering plants have no insects on them & $4.81(0.0603) b$ & $5.49(0.0382) \mathrm{a}$ & $5.3(0.0330)$ \\
\hline The plant was produced using bee-friendly practices & $4.27(0.0596) \mathrm{b}$ & $4.49(0.0429) \mathrm{a}$ & $4.4(0.0348)$ \\
\hline
\end{tabular}

report that pesticide residue was the fourth most important factor contributing to their purchasing decisions. Consumer demand for no pesticide residue on their plants, as shown in Table 9, is consistent with those reported in a survey of farm market consumers in eastern Kansas, where $93 \%$ were willing to pay $20 \%$ more for a U.S. number
1 grade carving pumpkin free of insecticides while $\approx 60 \%$ would be willing to pay $30 \%$ more (Olson et al., 1995). Surprisingly, in contrast to importance ranking 
Table 9. Production methods of importance. Participants listed the factors important in their purchasing decision from 1 (Strongly Disagree) to 7 (Strongly Agree). Comparisons between those who have purchased an ornamental plant in the past 12 months vs. those who have not purchased an ornamental plant in the past 12 months are in lower case letters in rows determined by using least square means with $P=0.05$ as a maximum value of significance. Comparisons in columns denoted by capital letters are done by paired $t$ tests with $P=0.05$ as a maximum value of significance.

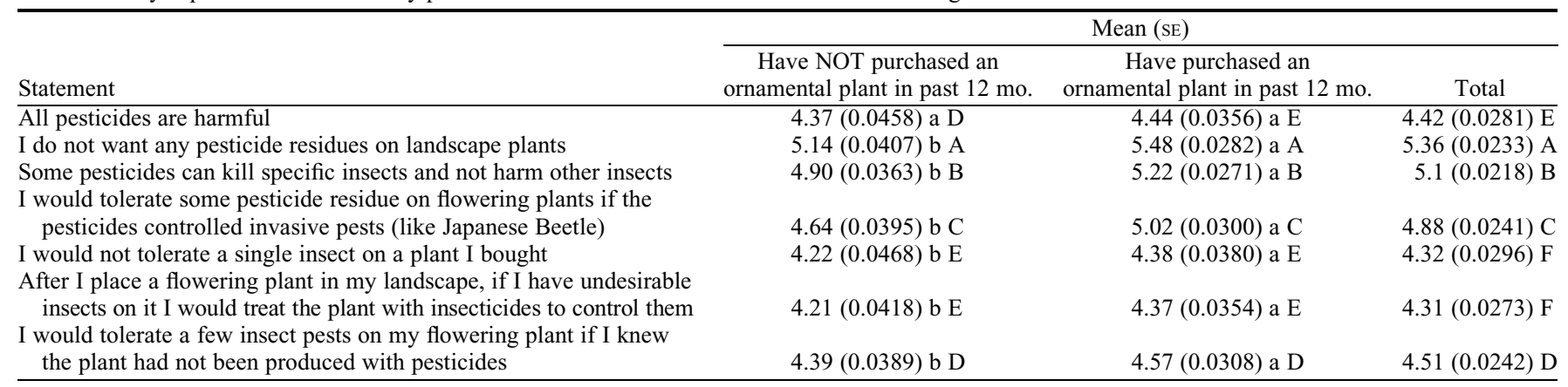

Table 10. Importance scores from conjoint analysis. Importance of price, production type, and species to consumers who have and have not purchased a plant in the last 12 months for the three conjoint studies. Lower case letters in rows compare each attribute between those participants that have and have not purchased a plant in the last $12 \mathrm{mo}$. using Tukey's honestly significant test with $P=0.05$ as a maximum value of significance. Upper case letters in columns represent differences between attributes using Tukey's honestly significant test with $P=0.05$ as a maximum value of significance.

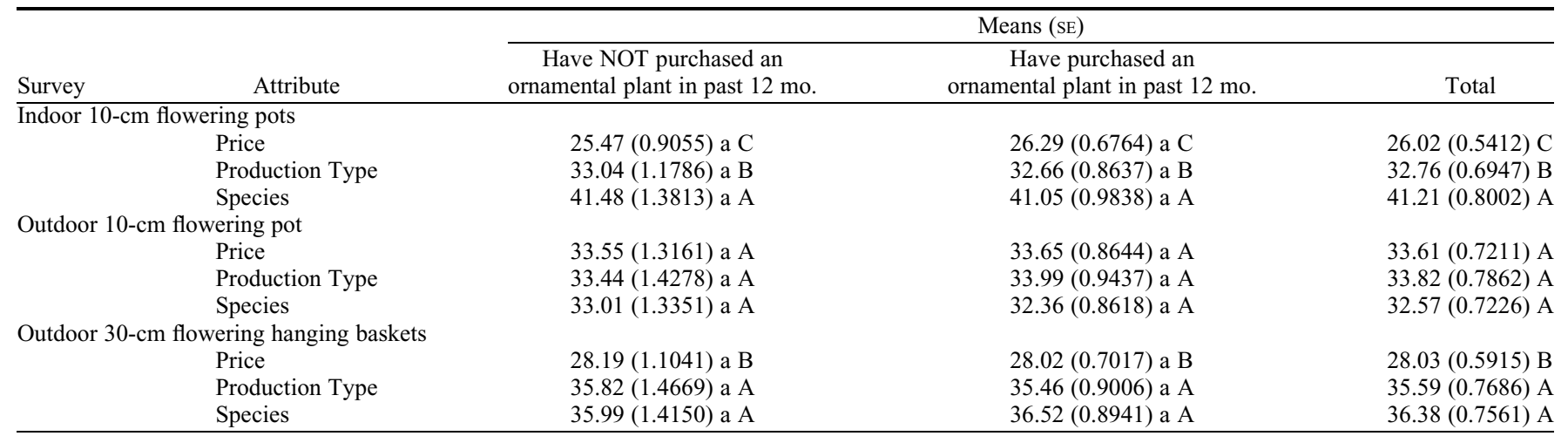

shown in Table 8 , respondents were the most neutral about the presence of a single insect on their plants.

The relative value of plant production method was consistent across surveys, with value scores ranging between 33 and 36 (Table 10). There was no difference in the relative importance of each of the factors (price, production type, or species) between respondents who had purchased a plant in the 12 months before the survey and those who had not. However, there were a few differences in the part-worth score for the levels within each attribute, indicating that some levels were more or less valuable to past plant purchasers compared with those who had not purchased a plant (Table 11). For example, the term "bee-friendly" is worth considerably more to those who had purchased a plant compared with those who had not. For the group that viewed the indoor $10-\mathrm{cm}$ flowering plant, "beefriendly" was five times more valuable to the group who had purchased ornamental plants compared with those who had not. But for both the group who viewed the $10-\mathrm{cm}$ flowering plant and $30-\mathrm{cm}$ flowering hanging basket, the gap in value was much smaller. Therefore, growers and retailers may need to develop a slightly separate marketing strategy based on past purchasing patterns.

\section{Summary and Conclusions}

In this study, we sought to better understand consumer preferences for pest management practices of floriculture crops. We conclude that marketing plants with the term "bee-friendly" would have the greatest impact on plant purchases because it had the highest part worth score and was the best understood term of those presented. For the subjects who viewed the outdoor plants, "bee-friendly" and "use of beneficial insects" had positive part-worth utility scores, but "neonicotinoid-free" and "traditional insect control" both had negative part-worth utility scores. The term "bee-friendly" is up to five times more valuable to those respondents that had bought a plant in the last 12 months compared with those who had not. Therefore, if ornamental plants are labeled with production practice, consumers will value the term "bee-friendly" the most and may discount products labeled "neonicotinoid-free."
The relative importance of labeling extrinsic characteristics, such as "beefriendly" to all survey respondents may provide the possibility of capturing premium prices with some demographic segments. For example, we concluded that plants labeled "bee-friendly" could capture $\$ 1.01, \$ 0.96$, or $\$ 2.10$ more than plants labeled with "grown with traditional pest management practices" for indoor $10-\mathrm{cm}$, outdoor $10-\mathrm{cm}$, or $30-\mathrm{cm}$ hanging baskets, respectively. Premium prices of plants labeled "bee-friendly" and the increasing concern about pesticide residues on ornamental plants, may push growers to consider biological control strategies. In a survey of $>1000$ greenhouse growers in 21 states in 2002, 60\% felt that biological control was unpractical in their setting, whereas $42 \%$ thought that biological control costs were too high (Marsh and Gallardo, 2009; Schumacher, 2002). The increasing concern of the use of the neonicotinoids as revealed in the public spotlight, increasing restrictions from retailers, and possible increasing governmental regulations may also push growers to alter their pest management practices. 
Table 11. Part-worth scores of price, production type, and species from three conjoint analyses for those respondents that have and have not purchased a plant in the last 12 months. Values are a numerical scoring of consumer preferences amongst all attributes and levels where a higher number indicates that consumers prefer that particular attribute or level over lower valued options. Lower case letters show differences within rows between participants that have and have not purchased a plant in the last 12 months. Upper case letters show differences within columns between attributes using Tukey's honestly significant test with $P=$ 0.05 as a maximum value of significance.

\begin{tabular}{|c|c|c|c|c|c|}
\hline \multirow[b]{2}{*}{ Survey } & \multirow[b]{2}{*}{ Attribute } & \multirow[b]{2}{*}{ Level } & \multicolumn{3}{|c|}{ Part-worth means (SE) } \\
\hline & & & $\begin{array}{l}\text { Have NOT purchased an } \\
\text { ornamental plant in past } 12 \mathrm{mo} \text {. }\end{array}$ & $\begin{array}{c}\text { Have purchased an } \\
\text { ornamental plant in past } 12 \mathrm{mo} \text {. }\end{array}$ & Total \\
\hline \multicolumn{6}{|c|}{ Indoor $10-\mathrm{cm}$ flowering pots } \\
\hline & \multicolumn{5}{|c|}{ Price } \\
\hline & & $\$ 2.99$ & $0.164(0.0191)$ a $\mathrm{A}$ & $0.173(0.0144)$ a A & $0.170(0.0114) \mathrm{A}$ \\
\hline & & $\$ 3.49$ & $0.033(0.0135)$ a $\mathrm{C}$ & $0.037(0.0102)$ a $\mathrm{D}$ & $0.037(0.0082) \mathrm{C}$ \\
\hline & & $\$ 3.99$ & $0.023(0.0149)$ a $C$ & $0.037(0.0109)$ a $\mathrm{D}$ & $0.031(0.0089) \mathrm{C}$ \\
\hline & & $\$ 4.49$ & $-0.220(0.0223)$ a $\mathrm{E}$ & $-0.247(0.0163)$ a $\mathrm{E}$ & $-0.238(0.0131) \mathrm{E}$ \\
\hline \multicolumn{6}{|c|}{ Production type } \\
\hline & & Bee friendly & $0.025(0.0254) \mathrm{b} \mathrm{C}$ & $0.126(0.0178)$ a $\mathrm{ABC}$ & $0.090(0.0147) \mathrm{BC}$ \\
\hline & & Beneficials & $0.049(0.0238)$ a $\mathrm{BC}$ & $0.037(0.0179)$ a D & $0.043(0.0143) \mathrm{C}$ \\
\hline & & NeonicFree & $0.052(0.0259)$ a BC & $0.056(0.0172)$ a CD & $0.054(0.0143) \mathrm{C}$ \\
\hline & & Traditional & $-0.126(0.0281)$ a $\mathrm{D}$ & $-0.219(0.0236) \mathrm{b} E$ & $-0.186(0.0183) \mathrm{D}$ \\
\hline \multicolumn{6}{|c|}{ Species } \\
\hline & & African violet & $0.058(0.0299)$ a $\mathrm{ABC}$ & $0.051(0.0218)$ a $\mathrm{D}$ & $0.051(0.0178) \mathrm{C}$ \\
\hline & & Hyacinth & $0.063(0.0260)$ a $\mathrm{ABC}$ & $0.093(0.0189)$ a BCD & $0.083(0.0152) \mathrm{BC}$ \\
\hline & & Mum & $0.161(0.0288)$ a $\mathrm{AB}$ & $0.150(0.0212)$ a $\mathrm{AB}$ & $0.154(0.0171) \mathrm{AB}$ \\
\hline & & Poinsettia & $-0.283(0.0381)$ a $\mathrm{E}$ & $-0.293(0.0287)$ a $E$ & $-0.288(0.0229) \mathrm{E}$ \\
\hline \multicolumn{6}{|c|}{ Outdoor $10-\mathrm{cm}$ flowering pots } \\
\hline & & $\$ 1.99$ & $0.246(0.0294) \mathrm{b} \mathrm{AB}$ & $0.321(0.0186)$ a $\mathrm{A}$ & $0.299(0.0157) \mathrm{A}$ \\
\hline & & $\$ 2.49$ & $0.112(0.0162) \mathrm{b}$ BCD & $0.16(0.0116)$ a BC & $0.146(0.0095) \mathrm{BC}$ \\
\hline & & $\$ 2.99$ & $0.021(0.0169) \mathrm{b} \mathrm{DE}$ & $-0.019(0.0106)$ a $\mathrm{EF}$ & $-0.009(0.009) \mathrm{E}$ \\
\hline & & $\$ 3.49$ & $-0.378(0.0329) b \mathrm{G}$ & $-0.461(0.0204)$ a I & $-0.437(0.0174) \mathrm{H}$ \\
\hline \multicolumn{6}{|c|}{ Production Type } \\
\hline & & Bee friendly & $0.158(0.0279)$ a $\mathrm{ABC}$ & $0.207(0.0177)$ a B & $0.192(0.0149) \mathrm{B}$ \\
\hline & & Beneficials & $0.105(0.0231)$ a CD & $0.120(0.0159)$ a $C D$ & $0.116(0.0131) \mathrm{CD}$ \\
\hline & & NeonicFree & $-0.023(0.0255)$ a $E$ & $-0.033(0.0170)$ a F & $-0.031(0.0141) \mathrm{E}$ \\
\hline & & Traditional & $-0.240(0.0345)$ a $F$ & $-0.294(0.0248)$ a H & $-0.278(0.0202) \mathrm{G}$ \\
\hline \multicolumn{6}{|c|}{ Species } \\
\hline & & Coreopsis & $-0.142(0.0265)$ a $F$ & $-0.127(0.0169)$ a $G$ & $-0.131(0.0142) \mathrm{F}$ \\
\hline & & Geranium & $-0.224(0.0310) \mathrm{b} \mathrm{F}$ & $-0.141(0.0219)$ a $\mathrm{G}$ & $-0.164(0.018) \mathrm{F}$ \\
\hline & & Pansy & $0.088(0.0292)$ a CDE & $0.057(0.0186)$ a DE & $0.066(0.0157) \mathrm{D}$ \\
\hline & & Petunia & $0.277(0.0305)$ a $\mathrm{A}$ & $0.211(0.0180)$ a B & $0.229(0.0155) \mathrm{B}$ \\
\hline \multicolumn{6}{|c|}{$\begin{array}{c}\text { Outdoor } 30-\mathrm{cm} \text { flowering hanging baskets } \\
\text { Price }\end{array}$} \\
\hline & & $\$ 12.99$ & $0.190(0.0212)$ a A & $0.205(0.0135)$ a A & $0.200(0.0114) \mathrm{A}$ \\
\hline & & $\$ 13.99$ & $0.076(0.0157)$ a $\mathrm{BC}$ & $0.058(0.0116)$ a $\mathrm{C}$ & $0.063(0.0094) \mathrm{D}$ \\
\hline & & $\$ 14.99$ & $-0.059(0.0149)$ a $\mathrm{DE}$ & $-0.077(0.0114)$ a FE & $-0.072(0.0091) \mathrm{F}$ \\
\hline & & $\$ 15.99$ & $-0.206(0.0217)$ a $F$ & $-0.186(0.0153)$ a $G$ & $-0.192(0.0125) \mathrm{G}$ \\
\hline \multicolumn{6}{|c|}{ Production type } \\
\hline & & Bee friendly & $0.123(0.0292) \mathrm{a} A B$ & $0.138(0.0189)$ a $\mathrm{AB}$ & $0.134(0.0159) \mathrm{BC}$ \\
\hline & & Beneficials & $0.080(0.0248)$ a $\mathrm{BC}$ & $0.058(0.0174)$ a CD & $0.065(0.0142) \mathrm{D}$ \\
\hline & & NeonicFree & $-0.056(0.0270)$ a $\mathrm{DE}$ & $-0.061(0.018)$ a FE & $-0.060(0.0149) \mathrm{EF}$ \\
\hline & & Traditional & $-0.147(0.0327)$ a FE & $-0.134(0.0225)$ a $F$ & $-0.140(0.0186) \mathrm{F}$ \\
\hline & species & Geranium & $-0201(00279)$ а F & $-0251(00214)$ a $G$ & $-0237(0,0172) \mathrm{G}$ \\
\hline & & Mixed container & $0.133(0.0292)$ a $\mathrm{AB}$ & $0.184(0.0203)$ a A & $0.170(0.0167) \mathrm{AB}$ \\
\hline & & New Guinea Impatiens & $-0.009(0.0246)$ a CD & $-0.020(0.0176)$ a DE & $-0.016(0.0143) \mathrm{E}$ \\
\hline & & Petunia & $0.076(0.0256)$ a $\mathrm{BC}$ & $0.087(0.0181)$ a BC & $0.083(0.0148) \mathrm{CD}$ \\
\hline
\end{tabular}

\section{Literature Cited}

Behe, B., B.L. Campbell, C.R. Hall, H. Khachatryan, J.H. Dennis, and C. Yue. 2013. Consumer preferences for local and sustainable plant production characteristics. HortScience 48: 200-208.

Behe, B., J. Hardy, S. Barton, J. Brooker, T. Fernandez, C. Hall, J. Hicks, R. Hinson, P. Knight, R. McNiel, T. Page, B. Rowe, C. Safley, and R. Schutzki. 2005a. Landscape plant material, size, and design sophistication increase perceived home value. J. Environ. Hort. 23(3):127-133.

Behe, B.K., R.M. Walden, M. Duck, B. Cregg, K. Kelley, and R.D. Lineberger. 2005b. Consumer preferences for and cost of production of tabletop Christmas trees. HortScience 40: 409-412.
Blacquiere, T., G. Smagghe, C.A.M. van Gestel, and V. Mommaerts. 2012. Neonicotinoids in bees: A review on concentrations, side-effects and risk assessment. Ecotoxicology 21:973992.

Butterfield, B. and I. Baldwin. 2013. National gardening survey. Conducted by the National Gardening Association, Williston, VT.

Chrzan, K. and B. Orme. 2000. An overview and comparison of design strategies for choicebased conjoint analysis. Sawtooth Software Research Paper Series, Sequim, WA.

Copping, L. 2013. Bees and neonicotinoids: The story continues. Outlooks on Pest Mgt. 24:109 119.

Cullen, R., K.D. Warner, M. Jonsson, and S.D. Wratten. 2008. Economics and adoption of conservation biological control. Biol. Control $45: 272-280$.
Gaasbeck, A. and V. Bouwman. 1991. Conjoint analysis in market research for horticultural products. Acta Hort.: Hort. Econ. Mktg. 295:121-125.

Grygorczyk, A., J. Turecek, and I. Lesschaeve. 2014. Consumer preferences for alternative pest management practices used during production of an edible and a non-edible greenhouse crop. J. Pest Sci. 87:249-258.

Hall, C., B. Campbell, B. Behe, C. Yue, J. Dennis, and R. Lopez. 2010. The appeal of biodegradable packaging to floral consumers. HortScience 45:583-591.

Hartigan, J.A. 1975. Clustering algorithms. Wiley, New York, NY.

Jetter, K. and T.D. Paine. 2004. Consumer preferences and willingness to pay for biological control in the urban landscape. Biol. Control 30:312-322. 
Klingeman, W.E., D.B. Eastwood, J.R. Brooker, C.R Hall, B.K. Behe, and P.R. Knight. 2004. Consumer survey identifies plant management awareness and added value of dogwood powdery mildew resistance. HortTechnology 14:275-282.

Kuhfeld, W.F. 2010. Marketing research methods in SAS. SAS Institute, Inc., Cary, NC.

Marsh, T.L. and K. Gallardo. 2009. Adopting biological control for ornamental crops in greenhouses. CAB Reviews: Perspectives Agri., Vet. Sci., Nutr., Nat. Resour. 4:1-9.

Mason, S., T. Starman, R.D. Lineberger, and B.K Behe. 2008. Consumer preferences for price, color harmony and care information of container gardens. HortScience 43:380-384.

Olson, D.L., J.R. Nechols, and C.W. Marr. 1995. Consumer's preference for insecticide-free pumpkins in eastern Kansas. HortTechnology 5:274-276.
Ott, S.L. 1990. Supermarket shopper's pesticide concerns and willingness to purchase certified pesticide residue-free produce. Agribusiness 6:593-602.

Schumacher, S.K. 2002. Economic analysis of production and pest management decisions confronting greenhouse growers. Kansas State Univ., Manhattan, KS, PhD Diss.

Thompson, G.D. and J. Kidwell. 1998. Explaining the choice of organic produce: Cosmetic defects, prices, and consumer preferences. Amer. J. Agr. Econ. 80:277-287.

Tomizawa, M. and J.E. Casida. 2005. Neonicotinoid insecticide toxicology: Mechanisms of selective action. Annu. Rev. Pharmacol. Toxicol. 45:247-268.

van Engelsdorp, D., J.D. Evans, C. Saegerman, C Mullin, E. Haubruge, B.K. Nguyen, M. Frazier, J. Frazier, D. Cox-Foster, Y. Chen, R. Underwood,
D.R. Tarpy, and J.S. Pettis. 2009. Colony collapse disorder: A descriptive study. Public Library of Science ONE 4:1-17.

Wells, R., W. Wilder, and J. Graham. 1994. Factors influencing purchases of nursery products in North Carolina. North Carolina Cooperative Extension, North Carolina Association of Nurserymen and North Carolina Department of Agriculture, Raleigh, NC

Yue, C., J.H. Dennis, B. Behe, C.R. Hall, B.L. Campbell, and R. Lopez. 2011. Investigating consumer preferences for organic, local, or sustainable plants. HortScience 46: 610-615.

Zagaden, Y., B.K. Behe, and R. Gough. 2008 Consumer preferences for native plants in Montana residential landscapes and perceptions for naturalistic designs. J. Environ. Hort. 26(2):109-114. 